\title{
VALOR NUTRICIONAL DA MERENDA E SUA CONTRIBUIÇÃO PARA AS RECOMENDAÇÕES NUTRICIONAIS DO PRÉ-ESCOLAR, MATRICULADO EM CEAPE*
}

\author{
Rosa Nilda Mazzilli**
}

\begin{abstract}
MAZZILLI, R.N. Valor nutricional da merenda e sua contribuição para as recomendações nutricionais do pré-escolar, matriculado em CEAPE. Rev. Saúde públ., S. Paulo, 21: 246-54, 1987.

RESUMO: Estudou-se o valor nutricional da merenda escolar e os vários tipos de preparações oferecidas aos pré-escolares, matriculados nos Centros de Educação e Alimentação do Pré-Escolar (CEAPEs). Analisou-se sua contribuição para satisfazer as recomendações diárias de energia e de nutrientes desse grupo etário da população. O estudo abrangeu 346 pré-escolares de CEAPEs implantados em 6 cidades do interior do Estado de São Paulo. As preparações servidas com maior freqüência em todos os CEAPEs foram: leite enriquecido, proteína testurizada de soja, sopas e mingaus de produtos à base dessa leguminosa. $\mathrm{O}$ valor energético médio variou de 210 a 403 calorias, e o de proteínas, de 5,7 a 12,0 g. Em relação a vitaminas e minerais, a merenda mostrou-se deficiente na maioria desses nutrientes e em todas as cidades estudadas. A contribuição da merenda para as recomendações diárias de energia e de proteína ficou entre 21 e $44 \%$ e de 13 a $26 \%$, respectivamente. Quanto ao teor vitamínico, a merenda atendeu ao previsto pelo PNAE em relação às vitaminas $\mathrm{A}, \mathrm{B}_{1} \mathrm{e}$ $\mathrm{B}_{2}$, apenas em três cidades; quanto aos minerais, somente o cálcio, em uma localidade, atingiu o estabelecido pelo Programa. A merenda ainda que não seja expressiva sua contribuição para as recomendações nutricionais diárias, constitui suplemento na dieta habitual do pré-escolar.
\end{abstract}

UNITERMOS: Nutrição da criança. Pré-escolares. Merenda escolar. Necessidades nutricionais.

\section{INTRODUÇÃO}

A alimentação suficiente e adequada, principal necessidade do ser humano ${ }^{6}$, constitui um dos direitos da criança ${ }^{7}$; todavia, especialmente nos países em desenvolvimento, milhares de crianças não estão desfrutando desse direito. Como consequêência, nessas áreas, a desnutrição protéico-energética (DPE) continua sendo um dos mais graves problemas de saúde pública.

A DPE, entre lactentes e pré-escolares de países em desenvolvimento, tem sido causa básica ou associada de mortalidade, contribuindo para elevar seu coeficiente nesses grupos populacionais ${ }^{9,28}$, chegando a ser de vinte a trinta vezes mais alta do que nos países desenvolvidos, na faixa etária de um a 4 anos $^{1}$.

Segundo a $\mathrm{OMS}^{27}$, a nutrição adequada é o principal fator para o crescimento e desenvolvimento normais.

Jelliffe e Jelliffe ${ }^{19}$ estimam que de um a dois terços dos 400 milhões de pré-escolares, existentes no Terceiro Mundo, sofrem de desnutrição.
No Brasil, os estudos realizados vêm demonstrando que a DPE é a deficiência nutricional de maior magnitude e conseqüência para a saúde s.3, $^{2,5,5,17,18}$.

Apesar da DPE afetar significativa percentagem de pré-escolares, somente o grupo de 0 a 2 anos deste segmento da população tem recebido, há mais tempo, a atenção dos Governos, seja em nível nacional ou estadual, mediante programas de assistência materno-infantil. Apenas recentemente as autoridades governamentais vêm se conscientizando da necessidade de dar atenção às crianças de 2 a 6 anos, faixa etária ainda sem atendimento, uma vez que a partir dos 7 anos já existiam os programas de assistência, tanto à saúde, nas unidades sanitárias, quanto à alimentação.

Tendo em vista o papel que a suplementação alimentar tem na dieta de seus beneficiários, principalmente na idade pré-escolar, e considerando as elevadas verbas que lhe são destinadas anualmente, tanto em níveis fe-

* Parte da Tese de Doutoramento, intitulada "Contribuição e interferência da merenda escolar no dia alimentar de crianças matriculadas em Centros de Educação e Alimentação do Pré-Escolar - CEAPs", apresentada ao Departamento de Nutrição da Faculdade de Saúde Pública da Universidade de São Paulo, para a obtenção do grau de doutor, em 1983.

* * Departamento de Nutrição da Faculdade de Saúde Pública da Universidade de São Paulo - Av. Dr. Arnaldo, 715 - 01255 - São Paulo, SP - Brasil. 
deral e estadual, quanto dos municípios, é de fundamental importância que se conheça o valor nutricional da suplementação alimentar oferecida, para aquilatar a validade desses programas.

O presente trabalho tem por objetivo investigar a contribuição da merenda escolar para as recomendações nutricionais diárias dos pré-escolares matriculados em Centros de Educação e Alimentação do Pré-Escolar CEAPEs*. Especificamente objetiva-se:

- Conhecer os tipos de merenda distribuídos nos CEAPEs.

- Analisar a merenda em termos de seu valor nutricional.

- Analisar a proporção de calorias e de nutrientes da merenda em relação às recomendações nutricionais e de energia, segundo a Tabela do National Research Council - NRC ${ }^{26}$, USA.

\section{METODOLOGIA}

\section{População de Estudo}

A pesquisa foi realizada em 6 cidades do interior paulista, nas quais funcionavam 26 CEAPEs. O estudo abrangeu 18 Unidades, pertencentes àqueles municípios, num total de 346 pré-escolares, cuja idade variou de 2 a 7 anos incompletos, no momento da extração da amostra. Empregou-se a amostragem probabilística em 3 etapas:

Primeira etapa: a unidade amostral foi o local do CEAPE. Segunda etapa: a unidade amostral foi a família. Terceira etapa: a unidade amostral foi o pré-escolar.

De cada família amostrada, na segunda etapa, selecionou-se, por sorteio, apenas uma criança dentre aquelas pertencentes à família sorteada.

\section{Método}

Os dados sobre as merendas servidas nos CEAPEs foram obtidos em cada Unidade, mediante entrevista com a merendeira, pessoa responsável pelo seu preparo e distribuição às crianças. Foram pesadas e/ou anotadas as quantidades mencionadas na embalagem de todos os alimentos utilizados no preparo dessa refeição escolar.

Para o cálculo da ingestão de calorias e de nutrientes empregou-se a Tabela de Composição Química dos Alimentos $^{32}$. Os valores para a vitamina A foram recalculados com base em equivalente retinol, usando-se a metodologia de Flores e col. ${ }^{10}$, por estarem assim expressas as recomendações do NRC, revisão $1980^{26}$.

Tendo em vista que os valores médios de energia e de cada nutriente, estabelecidos pelo NRC, constituem recomendações por faixa etária e esta abrange intervalo grande, julgou-se de interesse adaptá-los por ano de idade, visando a obter avaliação mais precisa da adequação da dieta do pré-escolar.

Assim, baseando-se nos dados de energia e proteína, recomendados para as faixas de 1 a 7 anos, idade das crianças da amostra, traçou-se uma curva para cada um daqueles dois elementos, com o auxílio da "curva francesa" (Fig. 1 e 2). A partir desses gráficos, utilizou-se o valor para energia e proteína correspondente, na curva, ao meio ano para cada idade, considerando-se que esta foi registrada em anos inteiros. Para o grupo de 7 anos, tomou-se o valor coincidente no ponto para a idade em anos inteiros. Incluiu-se esse grupo etário porque, embora, no momento do sorteio, fossem excluídas as crianças de 7 anos completos, no intervalo entre a seleção da amostra e o levantamento dos dados (aproximadamente 2 meses), 38 (11\%) pré-escolares completaram essa idade.

Os valores obtidos na curva serviram de base para o cálculo do total diário de energia e de proteína recomendado para os pré-escolares do estudo (Tabela 1).

\section{TABELA 1}

Valores de energia e proteína por $\mathrm{kg}$ de peso corporal, para as idades de 2 a 7 anos

\begin{tabular}{cccc}
\hline $\begin{array}{c}\text { Idade } \\
\text { (anos) }\end{array}$ & $\begin{array}{c}\text { Idade Ajustada } \\
\text { (anos) }\end{array}$ & $\begin{array}{c}\text { Energia } \\
\text { (Calor./kg de peso) }\end{array}$ & $\begin{array}{c}\text { Proteína } \\
\text { (g/kg de peso) }\end{array}$ \\
\hline 2 & 2,5 & 95,5 & 1,70 \\
3 & 3,5 & 91,0 & 1,62 \\
4 & 4,5 & 87,0 & 1,53 \\
5 & 5,5 & 85,0 & 1,44 \\
6 & 6,5 & 85,0 & 1,36 \\
7 & 7,0 & 85,0 & 1,32 \\
\hline
\end{tabular}

Desde que as necessidades de energia e de proteína estão diretamente relacionadas com o peso do indivíduo, utilizaram-se os valores médios do padrão de Santo André, Classe IV $^{20}$, para o referido cálculo.

A recomendação de tiamina, riboflavina e niacina está diretamente relacionada com a ingestão calórica; assim, as recomendações para esses nutrientes foram calculadas com base ao total calórico encontrado para as diferentes idades. Para os nutrientes restantes, ou seja, cálcio, fósforo, ferro, vitaminas $\mathrm{A}$ e $\mathrm{C}$, foram usados os valores tais como recomendados pelo $\mathrm{NRC}^{26}$. Com esses critérios, elaborou-se a tabela básica de recomendações de energia e nutrientes para o grupo estudado (Tabela 2).

\footnotetext{
* Trata-se programa que "tem como objetivo dar atendimento integral aos pré-escolares, principalmente àqueles das populações de baixa renda, fornecendo-lhes suplementação alimentar ao mesmo tempo que um programa específico de recreação orientada com o propósito de estimular o desenvolvimento físico, psicomotor, intelectual, social e emocional dessas crianças" (Gandra ${ }^{15}$ ) (cf. também Gandra ${ }^{13,14}$ ).
} 
TABELA 2

Recomendações de energia e de nutrientes, por idade,segundo sexo e peso*

\begin{tabular}{|c|c|c|c|c|c|c|c|c|c|c|c|c|}
\hline Idade & sexo & $\begin{array}{c}\text { Peso } \\
\mathrm{Kg}\end{array}$ & $\begin{array}{c}\text { Energia } \\
\text { Cal. }\end{array}$ & $\begin{array}{c}\text { Proteínas } \\
\mathrm{g}\end{array}$ & $\begin{array}{c}\text { Vit. A } \\
\mu \text { g E.R.** }\end{array}$ & $\begin{array}{l}\text { Vit. } B_{1} \\
\text { mg }\end{array}$ & $\begin{array}{c}\text { Vit. } B_{2} \\
\text { mg }\end{array}$ & $\begin{array}{c}\text { Niacina } \\
\text { mg }\end{array}$ & $\begin{array}{l}\text { Vit. A } \\
\text { mg }\end{array}$ & $\begin{array}{l}\text { Cálcio } \\
\text { mg }\end{array}$ & $\begin{array}{c}\text { Fósf. } \\
\mathrm{mg}\end{array}$ & $\begin{array}{c}\text { Ferro } \\
\mathrm{mg}\end{array}$ \\
\hline \multirow[t]{2}{*}{2 anos } & Masc. & 12.999 & 1.241 & 22 & 400 & 0,6 & 0,7 & 8,2 & 45 & 800 & 800 & 15 \\
\hline & Fem. & 12.512 & 1.195 & 21 & 400 & 0,6 & 0,7 & 7,9 & 45 & 800 & 800 & 15 \\
\hline \multirow[t]{2}{*}{3 anos } & Masc. & 14.869 & 1.353 & 24 & 400 & 0,7 & 0,8 & 8,9 & 45 & 800 & 800 & 15 \\
\hline & Fem. & 14.683 & 1.336 & 24 & 400 & 0,7 & 0,8 & 8,8 & 45 & 800 & 800 & 15 \\
\hline \multirow[t]{2}{*}{4 anos } & Masc. & 16.629 & 1.447 & 25 & 500 & 0,7 & 0,9 & 9,5 & 45 & 800 & 800 & 10 \\
\hline & Fem. & 16.595 & 1.444 & 25 & 500 & 0,7 & 0,9 & 9,5 & 45 & 800 & 800 & 10 \\
\hline \multirow[t]{2}{*}{5 anos } & Masc. & 18.673 & 1.587 & 27 & 500 & 0,8 & 0,9 & 10,5 & 45 & 800 & 800 & 10 \\
\hline & Fem. & 18.563 & 1.578 & 27 & 500 & 0,8 & 0,9 & 10,4 & 45 & 800 & 800 & 10 \\
\hline \multirow[t]{2}{*}{6 anos } & Masc. & 21.043 & 1.789 & 29 & 500 & 0,9 & 1,1 & 11,8 & 45 & 800 & 800 & 10 \\
\hline & Fem. & 20.674 & 1.757 & 28 & 500 & 0,9 & 1,0 & 11,6 & 45 & 800 & 800 & 10 \\
\hline \multirow[t]{2}{*}{7 anos } & Masc. & 23.584 & 2.005 & 31 & 700 & 1,0 & 1,2 & 13,2 & 45 & 800 & 800 & 10 \\
\hline & Fem. & 22.901 & 1.946 & 30 & 700 & 1,0 & 1,2 & 12,8 & 45 & 800 & 800 & 10 \\
\hline
\end{tabular}

* Pesos médios do padrão de Santo André, Classe IV ${ }^{20}$.

** $\mu$ g E.R. - $\mu$ g Equivalente Retinol.

Fonte: National Research Coucil ${ }^{26}$ (1980).

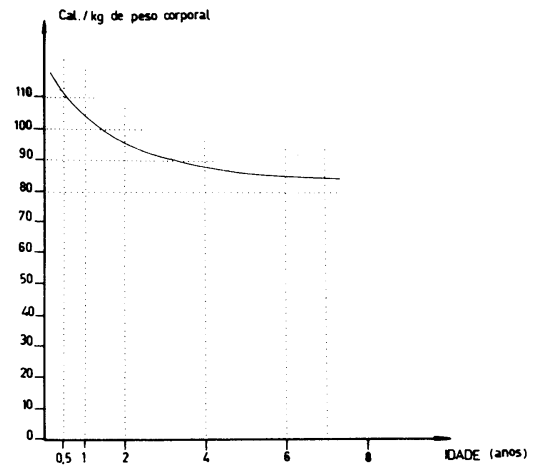

Fonte: National Research Council ${ }^{26}$ (1980)

Fig. 1 - Recomendações de calorias/kg de peso corporal, segundo idade, 1982, adaptada a partir das recomendações diárias de energia e nutrientes.

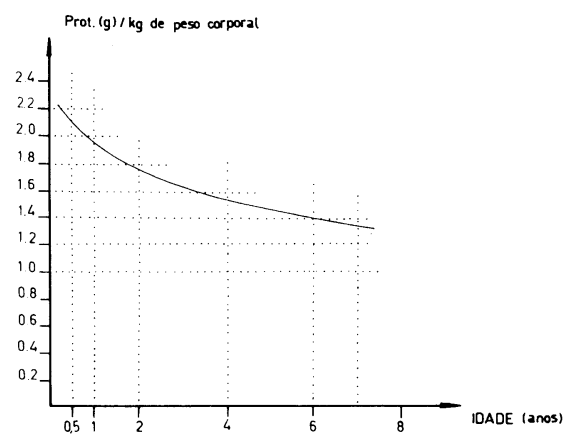

Fonte: National Research Council ${ }^{26}(1980)$

Fig. 2 - Recomendações de proteínas/kg de peso corporal, segundo idade, 1982, adaptada a partir das recomendações diárias de energia e nutrientes.

\section{RESULTADOS E COMENTÁRIOS}

\section{Tipos de Merenda Escolar}

O leite integral em pó, enriquecedores do leite*, proteína texturizada de soja**, sopas e mingaus dos mais variados tipos e sabores, sempre à base da referida leguminosa, foram os alimentos encontrados com maior freqüência em todos os CEAPEs. Esses produtos eram, na época, adquiridos pelo Departamento Estadual de Assistência ao Escolar (DAE), da Secretaria de Estado da Educação, e enviados às unidades conveniadas para execução do Programa de Merenda Escolar.

Assim, constatou-se que as preparações mais freqüentes, servidas na merenda, foram:

- sopas cremosas ou não, de cereal ou leguminosa em grão ou em pó, acrescidas de hortaliças, proteína texturizada de soja, ovos, carne ou seu caldo;

- macarronada, polenta, arroz doce e canjica;

- leite enriquecido, suco de laranja ou refresco e pão com margarina, doce ou proteína texturizada de soja (preparada como se fosse carne moída, com molho de tomate);

- leite enriquecido ou refresco e bolacha recheada.

Em alguns CEAPEs era distribuído, aos pré-escolares, leite enriquecido no momento da entrada e, posteriormente, a merenda em seu horário habitual.

\section{Valor Nutricional da Merenda Escolar}

Um dos objetivos deste estudo foi conhecer o valor nutricional das merendas servidas aos pré-escolares que freqüentam os CEAPEs. Constatou-se que, sem verbas

* Produtos à base de flavorizantes e açúcar, utilizados como aromatizantes do leite.

** Produto obtido a partir da farinha desengordurada de soja, submetida a processos industriais de texturização. 
adicionais especificamente destinadas a esse tipo de suplemento, ainda assim os municípios conseguem espontaneamente oferecer, às crianças do Programa, refeição que contribui com $13 \%$ a $26 \%$ das recomendações diárias de energia e $21 \%$ a $44 \%$ do recomendado para proteínas. Em alguns dos municípios integrantes do estudo, a merenda proporcionou boa contribuição referente ao total recomendado de vitaminas e minerais para esse grupo de crianças.

O valor nutricional médio das merendas servidas aos pré-escolares, nos vários CEAPEs pesquisados, foi diferente de uma cidade para outra (Tabela 3 ), de acordo com os recursos próprios de cada Município.

O total energético variou bastante, como pode ser observado na Tabela 3; o maior valor calórico da merenda, verificado em Lins, contribuiu, em média, com $24,4 \%$ para a ingestão total de calorias ${ }^{23}$ do grupo de pré-escolares (Tabela 4 ). Nas demais cidades essa contribuição média esteve entre $14,2 \%$ e $21,8 \%$. Esse percentual foi maior quando se considerou o consumo alimentar dos pré-escolares por faixa de idade e não do grupo como um todo (Tabela 4).

A quantidade de proteínas das merendas foi elevada, chegando sua contribuição a variar de 21 a $32 \%$ da ingestão média desse grupo, com exceção de Campinas, onde esse valor foi de 14\% (Tabela 5). Deve ser ressaltado que, ao lado dessa alta contribuição, a proporção de proteína de origem animal, em relação ao total, variou de 34 a 74\%. Assim, pode-se concluir que a merenda oferece boa suplementação desse nutriente, qualitativa e quantitativamente, sendo bem superior àquela proporcionada pela energia.

Quanto a vitaminas e minerais, as merendas mostraram-se inadequadas em relação ao que estabelece o II Programa Nacional de Alimentação e Nutrição (PRONAN II) ${ }^{17}$ : o suplemento alimentar deve atender a $30 \%$ das recomendações nutricionais diárias para esse grupo etário da população.

A merenda de Campinas mostrou-se inferior às das demais cidades no que se refere a vitaminas e minerais, exceto para o cálcio (Tabela 3 ), porque diariamente era servido leite enriquecido, enquanto nos outros CEAPEs os cardápios eram mais variados, como sopas diversas, macarronada, suco de laranja e, com menor freqüência, o leite, alimento este mais concentrado em cálcio.

\section{Qualidade Nutricional da Merenda Escolar}

Para analisar a qualidade nutricional da merenda (ME) consumida pelos pré-escolares, utilizou-se o "Índice de Qualidade Nutricional" (IQN), indicador atualmente empregado por vários estudiosos do assunto ${ }^{16,21 \text {, }}$ $30,31,34,35$.

As Figuras 3, 4, 5, 6, 7 e 8 indicam o IQN da ME e sua contribuição para satisfazer as recomendações diárias de energia e nutrientes do pré-escolar. Verifica-se que, em todas as cidades, esse valor está acima de 1,0 , mostrando que a merenda contém teor elevado de proteínas. A contribuição que faz para as recomendações é alta, variando de 35 a $44 \%$, exceção apenas para uma cidade (Fig. 5), na qual esse percentual é de apenas $21 \%$, não atingindo o previsto pelo Programa Nacional de Alimentação Escolar (PNAE) ${ }^{16}$. Entretanto, ao se observar o IQN das merendas oferecidas aos pré-escolares, nota-se que em todas as localidades está bem acima de 1,0 , ressaltando o seu valor nutricional em relação à proteína. Todavia, como esse indicador está relacionado com o total energético da dieta, tanto a ME, como também a dieta diária do grupo mostraram-se deficientes em calorias ${ }^{24}$, é de supor que parte dessa proteína seja utilizada como fonte de energia, prejudicando sua participação na síntese protéica orgânica ${ }^{8,25,29,33}$

Frente o alto custo dos alimentos protéicos e, ainda, considerando que dietas com elevado teor de proteína exigem maior dispêndio energético do organismo ${ }^{36}$, torna-se antieconômico atender às recomendações de calorias por meio da predominância de alimentos que representem boa fonte de proteína. Os hidratos de carbono e os lipídios, nutrientes principalmente energéticos, não só acarretam menor gasto de calorias orgânicas e liberam energia mais prontamente, como, também, são proporcionados por alimentos de mais baixo custo.

\section{TABELA 3}

Valor nutricional médio das merendas servidas nos CEAPEs das cidades estudadas. Estado de São Paulo, 1978/1979.

\begin{tabular}{|c|c|c|c|c|c|c|c|c|c|c|c|c|c|}
\hline \multirow[b]{2}{*}{ Cidades } & \multirow{2}{*}{$\begin{array}{c}\text { Energia } \\
\text { (Cal.) }\end{array}$} & \multicolumn{2}{|c|}{ Proteínas(g) } & \multirow{2}{*}{$\begin{array}{l}\text { Gordu- } \\
\text { ras } \\
\text { (g) }\end{array}$} & \multirow{2}{*}{$\begin{array}{c}\text { H.Carbono } \\
\text { (g) }\end{array}$} & \multirow{2}{*}{$\begin{array}{c}\text { Cálcio } \\
(\mathrm{mg})\end{array}$} & \multirow{2}{*}{$\begin{array}{l}\text { Fós- } \\
\text { foro } \\
\text { (mg) }\end{array}$} & \multirow{2}{*}{$\begin{array}{l}\text { Ferro } \\
(\mathrm{mg})\end{array}$} & \multirow{2}{*}{$\begin{array}{l}\text { Vit.A } \\
\text { (E.R.)* }\end{array}$} & \multirow{2}{*}{$\begin{array}{l}\text { Vit. } B_{1} \\
(\mathrm{mg})\end{array}$} & \multirow{2}{*}{$\begin{array}{l}\text { Vit. } B_{2} \\
(\mathrm{mg})\end{array}$} & \multirow{2}{*}{$\begin{array}{l}\text { Niaci- } \\
\text { na } \\
(\mathrm{mg})\end{array}$} & \multirow{2}{*}{$\begin{array}{l}\text { Vit.C } \\
\text { (mg) }\end{array}$} \\
\hline & & Totais & $\begin{array}{l}\text { Ani- } \\
\text { mais }\end{array}$ & & & & & & & & & & \\
\hline Campinas & 210 & 5,7 & 3,9 & 6,4 & 32,2 & 150 & 119 & 0,5 & 47 & 0,08 & 0,25 & 0,45 & 1 \\
\hline Guaratinguetá & 336 & 9,9 & 2,3 & 9 , & 53,0 & 147 & 165 & 1.4 & 60 & 0,2 & 0,25 & 0,98 & 6 \\
\hline Leme & 266 & 9,8 & 5,1 & 7,9 & 39,1 & 118 & 175 & 1,6 & 79 & 0,11 & 0,25 & 1,43 & 8 \\
\hline Lins & 403 & 10,9 & 3,6 & 13,6 & 64,8 & 116 & 179 & 1,8 & 38 & 0,12 & 0,22 & 1,21 & 3 \\
\hline Sumaré & 338 & 12,0 & 8,9 & 10,6 & 48,0 & 300 & 294 & 1,3 & 88 & 0,15 & 0,49 & 0,99 & 5 \\
\hline Suzano & 309 & 10,7 & 3,6 & 9,2 & 49,4 & 167 & 187 & 1,5 & 102 & 0,14 & 0,26 & 1,27 & 10 \\
\hline Médias** & 324 & 10,6 & 4,8 & 10,6 & 40,9 & 183 & 202 & 1,4 & 77 & 0,14 & 0,30 & 1,07 & 7 \\
\hline
\end{tabular}

* E.R Equivalente Retinol.

** A média das merendas foi ponderada em relação ao número de merendas em cada cidade estudada. 
TABELA 4

Adequação do consumo médio diário de calorias, valor médio calórico da merenda (M.E.) e sua contribuição energética no dia alimentar do pré-escolar (P.E.), segundo as cidades estudadas. Estado de São Paulo, 1978/1979.

\begin{tabular}{|c|c|c|c|c|c|c|c|c|c|}
\hline \multirow[b]{3}{*}{ Cidades } & \multirow[b]{3}{*}{$\begin{array}{l}\text { Idade } \\
\text { (anos) }\end{array}$} & \multirow[b]{3}{*}{$\begin{array}{l}\text { Número de } \\
\text { Pré-Escolares }\end{array}$} & \multicolumn{6}{|c|}{ Alimentação diária do pré-escolar } & \multirow{3}{*}{$\begin{array}{c}\text { Contribuição } \\
\text { da M.E. no } \\
\text { dia alimen- } \\
\text { tar do P.E. } \\
(\%)\end{array}$} \\
\hline & & & \multicolumn{3}{|c|}{ Refeições } & \multicolumn{3}{|c|}{ Merenda Escolar } & \\
\hline & & & $\begin{array}{c}\text { Recomen- } \\
\text { dação } \\
\text { Diária } \\
\text { (Cal) } \\
\end{array}$ & $\begin{array}{l}\text { Inges- } \\
\text { tão } \\
\text { Diária } \\
(\mathrm{Cal}) \\
\end{array}$ & $\begin{array}{c}\text { Adequação } \\
(\%) \\
\end{array}$ & $\begin{array}{c}\text { Recomen- } \\
\text { dação } \\
30 \% \\
(\text { Cal) }\end{array}$ & $\begin{array}{l}\text { Inges- } \\
\text { tão } \\
(\mathrm{Cal}) \\
\end{array}$ & $\begin{array}{c}\text { Adequação } \\
(\%)\end{array}$ & \\
\hline Campinas & $\begin{array}{l}<4 \\
4 \vdash 5 \\
5 \vdash 6 \\
6 \vdash 8 \\
\text { Total }\end{array}$ & $\begin{array}{r}7 \\
7 \\
25 \\
26 \\
65 \\
\end{array}$ & $\begin{array}{l}1315 \\
1484 \\
1600 \\
1860 \\
1664 \\
\end{array}$ & $\begin{array}{l}1403 \\
1315 \\
1475 \\
1557 \\
1483 \\
\end{array}$ & $\begin{array}{r}107 \\
89 \\
92 \\
84 \\
89 \\
\end{array}$ & $\begin{array}{l}394 \\
445 \\
480 \\
558 \\
499 \\
\end{array}$ & $\begin{array}{l}210 \\
210 \\
210 \\
210 \\
210 \\
\end{array}$ & $\begin{array}{l}53 \\
47 \\
44 \\
38 \\
42 \\
\end{array}$ & $\begin{array}{l}15,0 \\
16,0 \\
14,2 \\
13,5 \\
14,2 \\
\end{array}$ \\
\hline Guaratinguetá & $\begin{array}{l}\quad<4 \\
4 \vdash 5 \\
5 \vdash 6 \\
6 \vdash 8 \\
\text { Total }\end{array}$ & $\begin{array}{r}2 \\
4 \\
8 \\
14 \\
28 \\
\end{array}$ & $\begin{array}{l}1339 \\
1466 \\
1590 \\
1803 \\
1661 \\
\end{array}$ & $\begin{array}{l}1909 \\
1518 \\
1702 \\
1938 \\
1809 \\
\end{array}$ & $\begin{array}{l}142 \\
104 \\
107 \\
107 \\
109 \\
\end{array}$ & $\begin{array}{l}402 \\
440 \\
477 \\
541 \\
498 \\
\end{array}$ & $\begin{array}{l}336 \\
336 \\
336 \\
336 \\
336 \\
\end{array}$ & $\begin{array}{l}84 \\
76 \\
70 \\
62 \\
67 \\
\end{array}$ & $\begin{array}{l}17,6 \\
22,1 \\
19,7 \\
17,3 \\
18,6 \\
\end{array}$ \\
\hline Leme & $\begin{array}{l}<4 \\
4 \vdash 5 \\
5 \vdash 6 \\
6 \vdash 8 \\
\text { Total }\end{array}$ & $\begin{array}{r}- \\
1 \\
17 \\
31 \\
49 \\
\end{array}$ & $\begin{array}{c}- \\
1448 \\
1594 \\
1816 \\
1732 \\
\end{array}$ & $\begin{array}{c}- \\
1867 \\
1582 \\
1457 \\
1509 \\
\end{array}$ & $\begin{array}{r}- \\
129 \\
99 \\
80 \\
87 \\
\end{array}$ & $\begin{array}{c}- \\
434 \\
478 \\
545 \\
520 \\
\end{array}$ & $\begin{array}{c}- \\
266 \\
266 \\
266 \\
266 \\
\end{array}$ & $\begin{array}{l}- \\
61 \\
56 \\
49 \\
51 \\
\end{array}$ & $\begin{array}{c}- \\
14,2 \\
16,8 \\
18,2 \\
17,6 \\
\end{array}$ \\
\hline Lins & $\begin{array}{l}<4 \\
4 \vdash 5 \\
5 \vdash 6 \\
6 \vdash 8 \\
\text { Total }\end{array}$ & $\begin{array}{r}7 \\
10 \\
19 \\
5 \\
41 \\
\end{array}$ & $\begin{array}{l}1299 \\
1458 \\
1590 \\
1857 \\
1540 \\
\end{array}$ & $\begin{array}{l}1654 \\
1571 \\
1687 \\
1660 \\
1650 \\
\end{array}$ & $\begin{array}{r}127 \\
108 \\
106 \\
89 \\
107 \\
\end{array}$ & $\begin{array}{l}390 \\
437 \\
477 \\
557 \\
462 \\
\end{array}$ & $\begin{array}{l}403 \\
403 \\
403 \\
403 \\
403 \\
\end{array}$ & $\begin{array}{r}103 \\
92 \\
84 \\
72 \\
87 \\
\end{array}$ & $\begin{array}{l}24,4 \\
25,6 \\
23,9 \\
24,3 \\
24,4 \\
\end{array}$ \\
\hline Sumaré & $\begin{array}{l}\quad<4 \\
4 \vdash 5 \\
5 \vdash 6 \\
6 \vdash 8 \\
\text { Total }\end{array}$ & $\begin{array}{r}6 \\
10 \\
13 \\
22 \\
51 \\
\end{array}$ & $\begin{array}{l}1341 \\
1458 \\
1594 \\
1774 \\
1615 \\
\end{array}$ & $\begin{array}{l}1594 \\
1509 \\
1620 \\
1523 \\
1553 \\
\end{array}$ & $\begin{array}{r}119 \\
103 \\
102 \\
86 \\
96 \\
\end{array}$ & $\begin{array}{l}402 \\
437 \\
478 \\
532 \\
484 \\
\end{array}$ & $\begin{array}{l}338 \\
338 \\
338 \\
338 \\
338 \\
\end{array}$ & $\begin{array}{l}84 \\
77 \\
71 \\
64 \\
70 \\
\end{array}$ & $\begin{array}{l}21,2 \\
22,4 \\
20,9 \\
22,2 \\
21,8 \\
\end{array}$ \\
\hline Suzano & $\begin{array}{l}\quad<4 \\
4 \vdash 5 \\
5 \vdash 6 \\
6 \vdash 8 \\
\text { Total }\end{array}$ & $\begin{array}{r}- \\
2 \\
30 \\
80 \\
112\end{array}$ & $\begin{array}{c}- \\
1448 \\
1596 \\
1830 \\
1760\end{array}$ & $\begin{array}{c}- \\
2361 \\
1791 \\
1770 \\
1786\end{array}$ & $\begin{array}{r}- \\
163 \\
112 \\
97 \\
101\end{array}$ & $\begin{array}{l}- \\
434 \\
479 \\
549 \\
528\end{array}$ & $\begin{array}{c}- \\
308 \\
308 \\
308 \\
308\end{array}$ & $\begin{array}{l} \\
71 \\
64 \\
56 \\
58\end{array}$ & $\begin{array}{c}- \\
13,0 \\
17,2 \\
17,4 \\
17,2\end{array}$ \\
\hline
\end{tabular}

Fonte: Mazzilli ${ }^{23}(1983)$

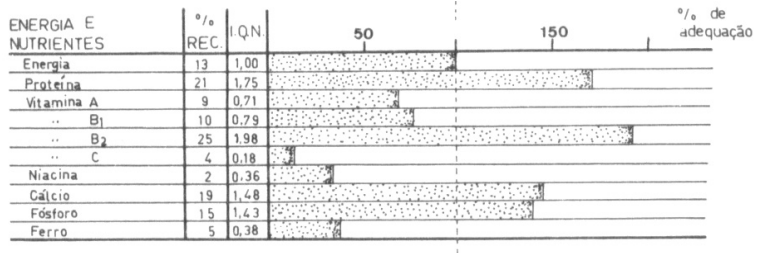

recomendado

Fig. 3 - Contribuição da merenda para as recomendações diárias de energia e nutrientes dos pré-escolares, matriculados em CEAPEs de Campinas, SP.

Convém ressaltar que o teor protéico das merendas oferece contribuição relativamente elevada para atender às recomendações diárias desse nutriente. Assim é que a merenda servida nos CEAPEs de todas as localidades estudadas, exceto Campinas, (Fig. 3), propicia de 35 a $44 \%$ das recomendações de proteínas para pré-escolares (Figs. 4, 5, 6, 7 e 8). Nota-se que, embora a me-

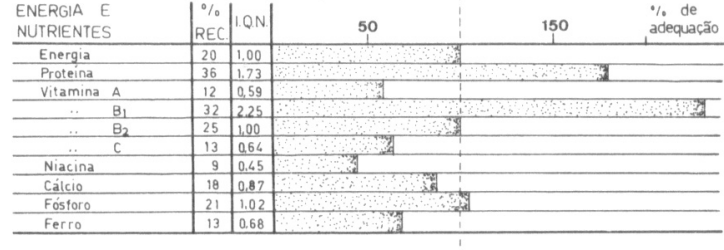

recomendado

Fig. 4 - Contribuição da merenda para as recomendações diárias de energia e nutrientes dos pré-escolares, matriculados em CEAPEs de Guaratinguetá, SP.

renda de Campinas seja constituída por menor teor protéico, 5,7g (Tabela 3), ainda assim representou $21 \%$ da quota recomendada desse nutriente para as crianças em estudo (Fig. 3).

Os resultados referentes à qualidade da merenda, no que diz respeito a vitaminas e minerais, mostraram si- 
TABELA 5

Adequação do consumo médio diário de proteína total da dieta, percentagem de proteína animal da dieta e da merenda (M.E.), valor médio protéico da merenda e sua contribuição no dia alimentar do pré-escolar (P.E.), segundo as cidades estudadas. Estado de São Paulo, 1978/1979.

\begin{tabular}{|c|c|c|c|c|c|c|c|c|c|}
\hline \multirow[b]{3}{*}{ Cidades } & \multirow{3}{*}{$\begin{array}{l}\text { Idade } \\
\text { (anos) }\end{array}$} & \multirow{3}{*}{$\begin{array}{l}\text { Número de } \\
\text { Pré-Escolares }\end{array}$} & \multicolumn{7}{|c|}{ Proteína } \\
\hline & & & \multirow{2}{*}{$\begin{array}{l}\text { Recomenda- } \\
\text { ção Diária } \\
\text { (g) }\end{array}$} & \multirow{2}{*}{$\begin{array}{l}\text { Adequação } \\
\text { de Consumo } \\
(\%)\end{array}$} & \multicolumn{2}{|c|}{ Ingestão Diária } & \multicolumn{2}{|c|}{ Merenda } & \multirow{2}{*}{$\begin{array}{l}\text { Contribuição } \\
\text { da M.E. no } \\
\text { dia alimen- } \\
\text { tar do P.E }\end{array}$} \\
\hline & & & & & $\begin{array}{l}\text { Total } \\
(\mathrm{g}) \\
\end{array}$ & $\begin{array}{c}\text { Origem } \\
\text { Animal } \\
(\% 0)\end{array}$ & $\begin{array}{l}\text { Total } \\
\text { (g) } \\
\end{array}$ & $\begin{array}{c}\text { Origem } \\
\text { Animal } \\
(\%)\end{array}$ & \\
\hline Campinas & $\begin{array}{l}<4 \\
4 \vdash 5 \\
5 \vdash 6 \\
6 \vdash 8 \\
\text { Total }\end{array}$ & $\begin{array}{r}7 \\
7 \\
25 \\
26 \\
65\end{array}$ & $\begin{array}{l}23,4 \\
25,4 \\
27,0 \\
29,1 \\
27,3\end{array}$ & $\begin{array}{l}186 \\
142 \\
135 \\
146 \\
145\end{array}$ & $\begin{array}{l}43,6 \\
36,1 \\
36,4 \\
42,6 \\
39,6\end{array}$ & $\begin{array}{l}36,7 \\
46,3 \\
53,0 \\
49,5 \\
48,9\end{array}$ & $\begin{array}{l}5,7 \\
5,7 \\
5,7 \\
5,7 \\
5,7\end{array}$ & $\begin{array}{l}68,4 \\
68,4 \\
68,4 \\
68,4 \\
68,4\end{array}$ & $\begin{array}{l}13,1 \\
15,8 \\
15,6 \\
13,4 \\
14,4\end{array}$ \\
\hline Guaratinguetá & $\begin{array}{l}<4 \\
4 \vdash 5 \\
5 \vdash 6 \\
6 \vdash 8 \\
\text { Total } \\
\end{array}$ & $\begin{array}{r}2 \\
4 \\
8 \\
14 \\
28 \\
\end{array}$ & $\begin{array}{l}24,0 \\
25,2 \\
27,0 \\
28,0 \\
27,0 \\
\end{array}$ & $\begin{array}{l}227 \\
178 \\
163 \\
167 \\
171 \\
\end{array}$ & $\begin{array}{l}54,5 \\
44,8 \\
44,1 \\
46,8 \\
46,3 \\
\end{array}$ & $\begin{array}{l}51,4 \\
39,7 \\
54,0 \\
47,4 \\
48,4 \\
\end{array}$ & $\begin{array}{l}9,9 \\
9,9 \\
9,9 \\
9,9 \\
9,9\end{array}$ & $\begin{array}{l}23,2 \\
23,2 \\
23,2 \\
23,2 \\
23,2 \\
\end{array}$ & $\begin{array}{l}18,2 \\
22,1 \\
22,4 \\
21,2 \\
21,4 \\
\end{array}$ \\
\hline Leme & $\begin{array}{l}<4 \\
4 \vdash 5 \\
5 \vdash 6 \\
6 \vdash 8 \\
\text { Total }\end{array}$ & $\begin{array}{r}- \\
1 \\
17 \\
31 \\
49\end{array}$ & $\begin{array}{r}- \\
25,0 \\
27,0 \\
28,6 \\
28,0\end{array}$ & $\begin{array}{c}- \\
241 \\
157 \\
139 \\
146 \\
\end{array}$ & $\begin{array}{c}- \\
60,3 \\
42,3 \\
39,7 \\
41,0\end{array}$ & $\begin{array}{l}- \\
64,2 \\
59,3 \\
57,7 \\
58,5 \\
\end{array}$ & $\begin{array}{l}- \\
9,8 \\
9,8 \\
9,8 \\
9,8\end{array}$ & $\begin{array}{l}- \\
52,0 \\
52,0 \\
52,0 \\
52,0\end{array}$ & $\begin{array}{l}- \\
16,2 \\
23,2 \\
24,7 \\
23,9\end{array}$ \\
\hline Lins & $\begin{array}{l}<4 \\
4 \vdash 5 \\
5 \vdash 6 \\
6 \vdash 8 \\
\text { Total }\end{array}$ & $\begin{array}{r}7 \\
10 \\
19 \\
5 \\
41\end{array}$ & $\begin{array}{l}23,3 \\
25,4 \\
27,0 \\
29,0 \\
26,2\end{array}$ & $\begin{array}{l}189 \\
164 \\
166 \\
176 \\
170 \\
\end{array}$ & $\begin{array}{l}44,0 \\
41,8 \\
44,9 \\
51,1 \\
44,7\end{array}$ & $\begin{array}{l}53,2 \\
47,8 \\
36,1 \\
46,4 \\
42,8 \\
\end{array}$ & $\begin{array}{l}10,9 \\
10,9 \\
10,9 \\
10,9 \\
10,9\end{array}$ & $\begin{array}{l}33,0 \\
33,0 \\
33,0 \\
33,0 \\
33,0 \\
\end{array}$ & $\begin{array}{l}24,8 \\
26,1 \\
24,3 \\
21,3 \\
24,3 \\
\end{array}$ \\
\hline Sumaré & $\begin{array}{l}<4 \\
4 \vdash 5 \\
5 \vdash 6 \\
6 \vdash 8 \\
\text { Total }\end{array}$ & $\begin{array}{r}6 \\
10 \\
13 \\
22 \\
51\end{array}$ & $\begin{array}{l}24,0 \\
25,4 \\
27,0 \\
28,0 \\
26,8 \\
\end{array}$ & $\begin{array}{l}176 \\
154 \\
140 \\
123 \\
138 \\
\end{array}$ & $\begin{array}{l}42,2 \\
39,1 \\
37,8 \\
34,4 \\
37,1 \\
\end{array}$ & $\begin{array}{l}65,4 \\
53,2 \\
50,5 \\
39,0 \\
48,5 \\
\end{array}$ & $\begin{array}{l}12,0 \\
12,0 \\
12,0 \\
12,0 \\
12,0 \\
\end{array}$ & $\begin{array}{l}74,2 \\
74,2 \\
74,2 \\
74,2 \\
74,2 \\
\end{array}$ & $\begin{array}{l}28,4 \\
30,7 \\
31,2 \\
34,9 \\
32,3 \\
\end{array}$ \\
\hline Suzano & $\begin{array}{l}<4 \\
4 \vdash 5 \\
5 \vdash 6 \\
6 \vdash 8 \\
\text { Total }\end{array}$ & $\begin{array}{r}- \\
2 \\
30 \\
80 \\
112\end{array}$ & $\begin{array}{l}- \\
21,0 \\
27,0 \\
28,7 \\
28,1\end{array}$ & $\begin{array}{l}- \\
280 \\
177 \\
175 \\
177\end{array}$ & $\begin{array}{c}- \\
58,8 \\
47,8 \\
50,2 \\
49,7\end{array}$ & $\begin{array}{r}- \\
47,4 \\
49,5 \\
46,8 \\
47,5\end{array}$ & $\begin{array}{c}- \\
10,7 \\
10,7 \\
10,7 \\
10,7\end{array}$ & $\begin{array}{l}- \\
33,6 \\
33,6 \\
33,6 \\
33,6\end{array}$ & $\begin{array}{c}- \\
18,2 \\
22,4 \\
21,3 \\
21,5\end{array}$ \\
\hline
\end{tabular}

Fonte: Mazzilli $^{23}(1983)$

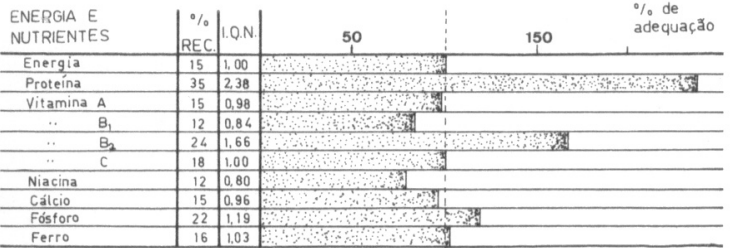

recomendado

Fig. 5 - Contribuição da merenda para as recomendações diárias de energia e nutrientes dos pré-escolares, matriculados em CEAPEs de Leme, SP.

tuação inversa ao que ocorreu com a proteína.

Analisando-se a contribuição da merenda em relação às quantidades diárias recomendadas de vitaminas, constatou-se que a refeição servida nos CEAPEs, em todas as localidades estudadas, somente em relação à vitami-

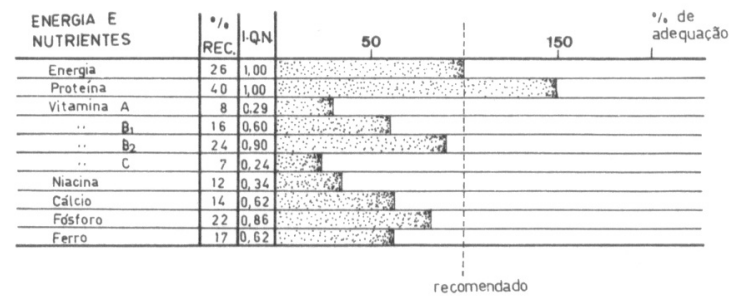

Fig. 6 - Contribuição da merenda para as recomendações diárias de energia e nutrientes dos pré-escolares, matriculados em CEAPEs de Lins, SP.

na $B_{2}$ é que se aproxima do percentual estabelecido pelo PRONAN II $^{16}$. Em relação à vitamina $C$, a contribuição maior da merenda encontrou-se em Suzano (Figura 8). Nesse Município, o suco de laranja, fonte de vitamina $C$, fazia parte da merenda. Quanto às demais vitaminas, a contribuição da merenda, de modo geral, não 


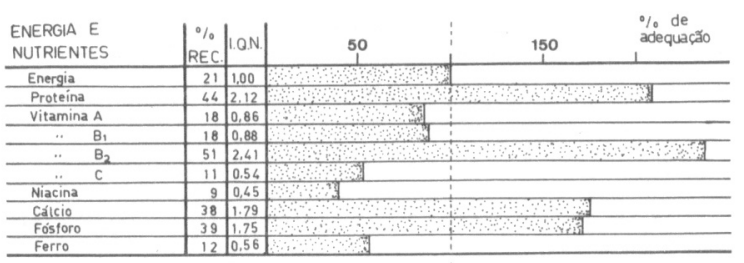

recomendado

Fig. 7 - Contribuição da merenda para as recomendações diárias de energia e nutrientes dos pré-escolares, matriculados em CEAPEs de Sumaré, SP.

foi relevante.

O IQN do cálcio da merenda foi elevado, variando de 0,87 a 1,79 , contribuindo com percentual entre 14 a $38 \%$ das recomendações para o pré-escolar, exceto em Lins (Fig. 3, 4, 5, 6, 7 e 8). Contudo, apesar da importante participação da merenda, a dieta das crianças foi deficiente em cálcio, uma vez que se verificou existir adequação média de consumo apenas entre 50 a $70 \%$ das recomendações ${ }^{24}$.

Cumpre notar que o conteúdo relativamente alto de riboflavina e cálcio na merenda, possivelmente, ocorre por conta do leite, boa fonte desses nutrientes, que é servido freqüentemente nos CEAPEs.

A merenda de Suzano foi a que se mostrou mais próxima dos valores estabelecidos pelo PNAE, mas, mesmo assim, sua contribuição para a vitamina $B_{1}$, niacina e ferro não atingiu $20 \%$ do recomendado para o préescolar (Fig. 8).

A merenda que propiciou menor contribuição foi a de Campinas (Fig. 3), além de ser a de menor valor calórico, quando comparada com a das demais cidades.

A análise do valor nutricional leva a deduzir que há maior preocupação em atender ao teor protéico das merendas, em prejuízo dos demais nutrientes (vitaminas e minerais). Entretanto, justamente para esses princípios nutritivos é que deveria haver, paralelamente, preocupação por parte dos responsáveis pelo Programa, ao se verificar que a dieta usual de nossa população é bastante falha pelo escasso consumo de hortaliças, frutas e leite, alimentos esses fontes desses nutrientes - fato já comprovado por estudos anteriormente realizados ${ }^{11,24}$.

Paralelamente ao leite, se se utilizasse também, com freqüência e em quantidade apropriada, hortaliças e frutas, o PNAE não só estaria fornecendo suplementação adequada e corrigindo falhas alimentares, habitualmente encontradas em nosso meio, como também contribuiria para levar a criança ao hábito de incluir esses alimentos em sua dieta diária, fixando-o na vida adulta.

Considerando-se as diretrizes do PRONAN II ${ }^{16}$ para a suplementação alimentar de pré-escolares, ou seja, atender a $30 \%$ das necessidades diárias de energia e de

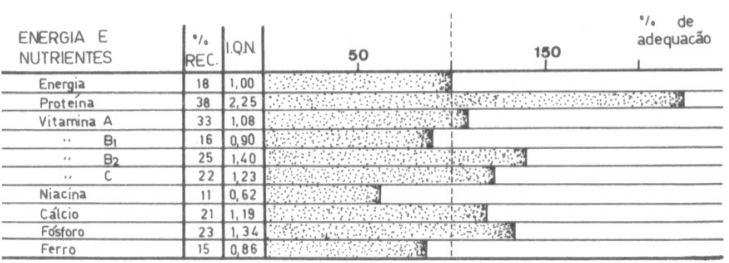

recomendado

Fig. 8 - Contribuição da merenda para as recomendações diárias de energia e nutrientes dos pré-escolares, matriculados em CEAPEs de Suzano, SP.

nutrientes dessas crianças, a merenda oferecida assim se comportou:

- quanto à energia, nenhuma das merendas atingiu o valor previsto;

- com referência às proteínas, com exceção de Campinas cuja média atingiu apenas $21 \%$ das recomendações protéicas, as das outras localidades superaram esse valor, paralelamente à inadequação calórica;

- no que se refere a vitaminas, as merendas só atendem às recomendações do PRONAN II quanto às vitaminas $\mathrm{A}, \mathrm{B}_{1}$ e $\mathrm{B}_{2}$ apenas, respectivamente, em Suzano, Guaratinguetá e Sumaré;

- em relação ao ferro, a merenda de nenhuma das localidades atendeu a sequer $20 \%$ das recomendações diárias desse mineral, enquanto que, em relação ao cálcio, apenas a merenda de Sumaré satisfaz aos requesitos do PRONAN II.

Mas, levando-se em conta que os municípios e a comunidade respondem por parcela maior de contribuição para a merenda dos CEAPEs, é de se esperar que esse Programa, alternativa de assistência aos pré-escolares que já se mostrou eficaz e eficiente, seja suportado amplamente também pelo Instituto Nacional de Assistência ao Estudante (INAE) e tenha, como meta, fornecer $30 \%$ das recomendações energéticas e de nutrientes às crianças que atende.

Entretanto, ressalta-se, que é de fundamental importância que os programas de suplementação alimentar sejam baseados nas necessidades alimentares de sua população - alvo, investigando quais os nutrientes limitantes de sua dieta ${ }^{22}$. Mas, esse conhecimento somente será possível mediante pesquisas sobre a alimentação dos grupos aos quais se destinam esse programa.

\section{CONCLUSÕES}

- O valor nutricional da merenda oferecida nos CEAPEs, ainda que não elevado, proporcionou de 13 a $26 \%$ das recomendações diárias de energia e de 21 a $44 \%$ do recomendado de proteína para o grupo estudado de pré-escolares.

- Quanto a vitaminas, a merenda não atende ao disposto no PRONAN II, com exceção para as vitaminas $A, B_{1}$ e $B_{2}$, respectivamente em Suzano, Guaratinguetá e Sumaré.

- Quanto aos minerais, também a merenda não al- 
cançou o estabelecido pelo PNAE: o ferro, em nenhuma das localidades alcançou, sequer, a $20 \%$ das recomendações diárias e, com relação ao cálcio, apenas em Sumaré satisfaz esse requisito do PRONAN II.

- Conquanto não fosse expressiva a contribuição da merenda, em termos de energia, vitaminas e minerais, ainda, assim, constituiu ela suplemento na dieta habitual do pré-escolar.

- É fundamental que os programas de suplementação alimentar sejam baseados em pesquisas prévias do consumo alimentar, não só do grupo-alvo como do consumo familiar, no sentido de contar com informações essenciais para planejamento adequado do suplemento a ser oferecido.

MAZZILLI, R. N. [The nutritional value of the school lunch and its contribution to the fulfilling of the nutritional recommendations of preschoolers enrolled in the Center for Education and Feeding of the Preschooler] Rev. Saúde públ., São Paulo, 21:246-54, 1987.

ABSTRACT: The present paper studied the nutritional value of the school lunch and the variety of the preparations offered to preschool children drawn from Preschool Education and Feeding Centres (CEAPE). Its contribution to the energy and nutrients intake of this population group was analysed. Three hundred and forty six preschool children belonging to six towns of the State of S. Paulo were studied. The preparations most often served in all the CEAPEs studied were enriched milk, soy texturized protein, soups and mushes including soy bean. The average energy value of the school lunch varied between 210 and 403 calories and between 5.7 and $12 \mathrm{~g}$ of protein. The school lunch contributed from 21 to 44 per cent of the recommended energy intake. It was only sufficient in vitamins $A, B_{1}$ and $B_{2}$ in three towns and in calcium in only one. Although the school lunch does not make a significant contribution, it is a supplement to the usual preschool diet.

UNITERMS: Child nutrition. Child, preschool. School lunch. Nutritional requirements.

\section{REFERÊNCIAS BIBLIOGRÁFICAS}

1. AISENBERG, M. et al. Estudios sobre desnutrición infantil. Sem. med., Buenos Aires, 146: 312-4, 1975.

2. ALMEIDA, I. S. de et al. Estado nutricional de crianças no primeiro ano de vida em comunidades rurais de Planaltina, Brasil, 1976. Bol. Ofic. sanit. panamer., 89: 546-52, 1980.

3. ALVES, E. L. G. Nível alimentar, renda e educação. Rev. ABIA-SAPRO, 30: 17-44, 1977.

4. BALDO, H. A. P. C. S. Má nutrição protéico-calórica de crianças de $0-5$ anos do Distrito de São Paulo. São Paulo, 1971. [Tese de Doutoramento - Faculdade de Saúde Pública da USP.]

5. BATISTA FILHO, M. Prevalência e estágios da desnutrição protéico-calórica em crianças da cidade de São Paulo. São Paulo, 1976. [Tese de Doutoramento - Faculdade de Saúde Pública da USP].

6. BERG, A. The nutrition factor. Washington, D. C., The Brookings Institution, 1973.

7. COMISSÃO SOCIAL DO CONSELHO ECONÔMICO E SOCIAL DA ONU. Declaração dos direitos da criança. Cor. Unesco, 7: 18-9, 1979.

8. COMITE ESPECIAL FAO/OMS DE EXPERTOS EN NECESIDADES DE ENERGIA Y DE PROTEINAS, Roma 1971. Necesidades de energia y de proteinas: informe. Ginebra, 1973. (OMS - Ser. Inf. tecn., 522).

9. ENDERICA, R. Edad mediana de mortalidad, indicador del desarollo economico-social y como tal del component nutricional. Arch. lat. - amer. Nutr., 27: 445-50, 1977.

10. FLORES, $M$. et al. Contenido de vitamina $A$ en los alimentos incluidos en la Tabla de Composición de Alimentos para uso en America Latina. Arch. lat. - amer. Nutr., 19: 311-41, 1969.

11. FUNDAÇÃO IBGE. Consumo alimentar, antropometria, dados preliminares. Região II: São Paulo, Região IV Minas Gerais e Espirito Santo. Rio de Janeiro, 1977. (Estudo Nacional da Despesa Familiar, v. 1, t.l, pt. 3).

12. GANDRA, Y. R. Assistencia alimentaria por médio de Centros de Educación y Alimentacion del Pré-Escolar. Bol. Ofic. sanit. panamer., 74: 302-14, 1973.

13. GANDRA, Y. R. Nutrition and dietetic education program for pre-school children at primary school in Brazil. In: Anderson, M. A. \& Grewal, T., ed. Nutrition planning in developing world: proceedings of regional workshops held by care in India, Kenya and Colombia, 1976. Bogotá, Programas Editoriales, 1976. p. 205-12.

14. GANDRA, Y. R. O pré-escolar de dois a seis anos de idade e o seu atendimento. Rev. Saúde públ., S. Paulo, 15 (supl.): 3-8, 1981.

15. HANSEN, R. G. An index of food quality. Nutr. Rev., 31: $1-7,1973$

16. INSTITUTO NACIONAL DE ALIMENTAÇÃO E NUTRIÇÃO. Programa Nacional de Alimentação e Nutrição (PRONAN II). Brasília, 1976. (Doc. Tecn. 06).

17. IUNES, E. S. M., coord. et al. Estado nutricional de crianças de 6 a 60 meses no Município de São Paulo: análise de dados. São Paulo, Instituto de Medicina Preventiva da Escola Paulista de Medicina/Instituto de Pesquisas Econômicas da USP, 1975. 2 v.

18. JANSEN, G. R. el al. Effect of income and geographic region on the nutritional value of the Brazil. Amer. J. clin. Nutr., 30: 955-64, 1977.

19. JELLIFFE, D. B. \& JELLIFFE, E. F. P. Nutrition programs for preschool children. Amer. J. clin. Nutr., 25: 595-805, 1961.

20. MARQUES, R. M. et al. Crescimento de niños brasileños: peso y altura en relación com la edad y el sexo y la influencia de factores socieconomicos. Washington, D. C., 
Organización Panamericana de la Salud, 1975. (OPAS - Publ. cient., 309).

21. MARTINS, I. S. "Índice de qualidade do alimento": uma medida de qualidade e de adequação de dietas. Rev. Saúde públ., S. Paulo, 16: 329-35, 1962.

22. MARTORELL, R. et al. Protein-calorie suplementation and post-natal physical growth: a review of findings from developing countries. Arch. lat. - amer. Nutr., 26: 115-28, 1976.

23. MAZZILLI, R. N. Contribuição e interferência da merenda escolar no dia alimentar de crianças matriculadas em Centros de Educação e Alimentação do Pré-Escolar. São Paulo, 1983. [Tese de Doutoramento - Faculdade de Saúde Pública da USP].

24. MAZZILLI, R. N. \& GANDRA, Y. R. Consumo alimentar de pré-escolares matriculados nos Centros de Educação e Alimentação do Pré-Escolar (CEAPEs) e de suas respectivas famílias. Rev. Saúde públ., S. Paulo, 15 (supl.): 23-32, 1981.

25. MOHAN, M. Nutritional requirements for infants and children. Indian Pediat., 14: 309-14, 1977.

26. NATIONAL ACADEMY OF SCIENCES. Recommended dietary allowances. $9^{\text {th }}$ ed. Washington, D.C., 1980.

27. ORGANIZACIÓN MUNDIAL DE LA SAUD. Grupo Cientifico sobre Desarrollo Humano y Salud Publica, Ginebra, 1971. Informe. Ginebra, 1972. (Ser. Inf. tecn., 485).

28. PUFFER, R. R. \& SERRANO, C. N. Caracteristicas de la mortalidad en la niñez: informe de la investigación interamericana de mortalidad en la niñez. Washington,
D. C., Organización Panamericana de Salud, 1975. (OPAS - Publ. cient., 262).

29. SALOMON, J. B. R. Fundamentos fisiológicos dos requerimentos nutricionais. In: Nobrega, F. J. de Desnutrição intra-uterina e pós-natal. São Paulo, Ed. Panamed, 1981. p. 30-4.

30. SORENSON, A. W. \& HANSEN, R. G. Index of food quality. J. Nutr. Educ., 7: 53-67, 1975.

31. SORENSON, A. W. et al. An index of nutritional quality for a balanced diet. J. Amer. diet. Ass., 68: 236-42, 1976.

32. UNIVERSIDADE DE SÃO PAULO. Faculdade de Saúde Pública. Departamento de Nutrição. Tabela da composição química de alimentos: compilação de várias tabelas nacionais e estrangeiras. São Paulo, 1971. [Mimeografado]

33. VALVERDE, V. et al. Revisión del aporte calórico e proteínico de las dietas de poblaciones de bajo nivel socioeconomico en Centro America. Existe un problema de proteinas? Arch. lat. - amer. Nutr., 25: 329-49, 1975.

34. WITTER, A. J. et al. Nutrient evaluation of nutritional attributes of food. J. Nutr. Educ., 9: 26-30, 1977.

35. WYSE, B. et al. Nutritional quality index identifies consumer nutrient needs. Food Technol., 30: 22-40, 1976.

36. WILSON, E. D. et al. Principles of nutrition. $4^{\text {th }}$ ed. New York, Willey, 1979.

Recebido para publicação em 07/11/1985 Reapresentado em 12/2/1987 Aprovado para publicação em 21/3/1987. 